\title{
1 Projected dynamics of breeding habitat suitability for a steppe-land bird \\ 2 warrant anticipatory conservation actions
}

3

4 Andrea Simoncini ${ }^{1^{*}}$, Samuele Ramellini ${ }^{2 *}$, Alexis Martineau ${ }^{3}$, Alessandro Massolo ${ }^{1,4,5}$, 5 Dimitri Giunchi ${ }^{1}$

6

$7 \quad{ }^{1}$ Dipartimento di Biologia, Università di Pisa, 56126 Pisa, Italy;

$8{ }^{2}$ Dipartimento di Scienze e Politiche Ambientali, Università degli Studi di Milano, 20133

9 Milano, Italy;

$10{ }^{3}$ Groupe Ornithologique des Deux-Sèvres, 48 rue Rouget de Lisle, 79000 Niort, France;

$11{ }^{4}$ Department of Ecosystem and Public Health, Faculty of Veterinary Medicine, University of 12 Calgary, Calgary, Alberta T2N 1N4, Canada;

$13{ }^{5}$ UMR CNRS 6249 Chrono-environnement, Université Bourgogne Franche-Comté, 25030

14 Besançon, France

16 *A. Simoncini and S. Ramellini should be considered as joint first authors.

18 Corresponding author: Dimitri Giunchi, Dipartimento di Biologia, Università di Pisa, via

19 Volta 6, 56126 Pisa (PI), Italy, dimitri.giunchi@unipi.it

21 Short title: Breeding suitability for a steppe-land bird 


\section{ABSTRACT}

2 Understanding spatial and temporal variations of habitat suitability is fundamental for

3 species' conservation under global change. Steppic species are particularly sensitive to

4 anthropogenic change and have undergone large declines in the last decades. We aimed to

5 describe current and future breeding habitat suitability for the Eurasian stone-curlew

6 Burhinus oedicnemus, a steppic species of conservation concern, and to identify critical areas

7 for its conservation. We collected 1628 presence records covering the period 1992-2016. We

8 developed a species distribution model using a dynamic Maxent algorithm and a set of

9 pseudo-absences with a spatial density weighted on a fixed kernel density estimated on the

10 presences, to mitigate the potential sampling bias. We projected this model under a set of

11 carbon emission, socioeconomic and land-use/land-cover scenarios for the years 2030, 2050,

122070 and 2090. Finally, we described the cell-wise and mean change of breeding habitat

13 suitability through consecutive time intervals and identified the areas critical for the species'

14 conservation.

15 All scenarios predicted a short-term northward shift of suitable areas, followed by a period of

16 stability. We found no consistent trends in the mean change of breeding habitat suitability,

17 and similar extents of suitable areas under current and future scenarios. Critical areas for the

18 conservation of the species are mainly located in Northern Europe, Israel and parts of North

19 Africa, the Iberian Peninsula and Italy. According to our results, the Eurasian stone-curlew

20 has the potential to maintain viable populations in the Western Palearctic, but dispersal

21 limitations might hinder the colonization of shifted suitable areas. Targeted conservation

22 interventions in the critical areas are therefore recommended to secure the future of the

23 species under global change.

24 Keywords: Eurasian stone-curlew, Burhinus oedicnemus, species distribution models, habitat 25 suitability, steppe-land, environmental change. 


\section{INTRODUCTION}

3 Human-driven environmental change has relevant impacts on the distribution and life-history

4 of organisms (Parmesan, 2006; Chen et al., 2011) and their likelihood of extinction (Román-

5 Palacios \& Wiens, 2020). Several studies reported distributional shifts in animal species

6 according to climate change (Vanderwal et al., 2013), physiological constraints (Root et al.,

7 2003) and in response to land-use and land-cover modifications (LULC; Sala et al., 2000). In

8 birds, habitat suitability is affected by both climate and LULC change (Barbet-Massin,

9 Thuiller, \& Jiguet, 2011), and its variation has been linked to population trends (Green et al.,

10 2008).

11 Steppe-land birds are particularly sensitive to environmental change, and large declines in 12 steppe-land birds' populations have been reported during the last decades, primarily as a 13 consequence of agricultural intensification and afforestation following land abandonment 14 (Burfield, 2005; Onrubia \& Andrés, 2005). The Eurasian stone-curlew Burhinus oedicnemus 15 (Linnaeus, 1758; hereafter stone-curlew) is a wide-ranging steppe-land species occurring in 16 pseudo-steppes and farmlands in the Palearctic (Vaughan \& Vaughan-Jennings, 2005). The 17 species suffered a severe population decline $(>30 \%)$ in the second half of the 20th century, 18 mainly due to agricultural intensification (BirdLife International, 2018). It is now classified 19 as Least Concern by the IUCN (BirdLife International, 2021), but information on the status of 20 its populations is limited and positive trends might be due to the increased monitoring effort 21 (Gaget et al., 2019). Indeed, the species is still considered of European conservation concern 22 (SPEC3; BirdLife International 2017), and ongoing declines are reported for many regions of 23 its range (BirdLife International, 2017; Gaget et al., 2019). Moreover, the stone-curlew is 24 considered both an umbrella and flagship species (Caro, 2010; Hunter et al., 2016), and its 25 conservation can therefore benefit steppe-land ecosystems (Hawkes et al., 2019). 
1 To establish effective conservation practices, state-of-the-art habitat suitability scenarios for

2 the focal species are required (Miller-Rushing, Primack, \& Sekercioglu, 2010; Mcshea,

3 2014), and rigorous analyses of suitability dynamics are essential to reveal the sensitivity of

4 species to global change and to guide conservation efforts (Stiels et al., 2021). Moreover,

5 recent studies are increasingly evidencing the importance of distinguishing between the

6 effects of long-term vs. short-term environmental change (Reside et al., 2010; Milanesi, Della

7 Rocca, \& Robinson, 2020). Previous studies using species distribution models (SDM, Guisan

8 \& Zimmermann 2000) to model habitat suitability for steppe-land birds reported northern

9 range shifts and the persistence of large suitable areas according to global change scenarios

10 (Estrada et al., 2016; Kiss et al., 2020). Huntley et al. (2007) used SDMs to forecast the

11 future distribution of the stone-curlew under climate change scenarios, highlighting a

12 northward shift of suitable areas.

13 Their analysis was limited to a coarse scale (ca. $50 \mathrm{~km}$ ), Europe, one future period (end of the

$1421^{\text {st }}$ century) and a single climate scenario. An in-depth analysis integrating LULC and a

15 range of climatic scenarios might validate their conclusions and provide time-varying

16 predictions for conservation practitioners.

17 Therefore, in this study we aimed to: (i) test whether the stone-curlew's distribution is driven

18 by long-term or short-term environmental conditions, (ii) describe the current availability of

19 suitable breeding habitats for stone-curlew, (iii) provide a range of future breeding habitat

20 suitability scenarios considering both climate and LULC changes, (iv) test the hypothesis of a

21 Northern shift for the stone-curlew, at higher spatial resolution than Huntley et al. (2007) and

22 on multiple time-steps, and (v) identify the critical areas for its conservation. We predicted

23 that (1) our models would highlight a northern shift of suitable breeding areas for the stone-

24 curlew, (2) large areas of the Western Palearctic would be suitable for the species under

25 future scenarios. As the stone-curlew is a species of warm temperate areas, it is unlikely that 
mean breeding habitat suitability will drop rapidly with global warming, as this is fastest at northern latitudes (IPCC, 2013). Therefore, we also predicted a stable or increasing mean breeding habitat suitability for the species under future conditions.

\section{MATERIALS AND METHODS}

\section{Spatial scale}

To reduce the spatial extent while retaining sufficient environmental variation, we limited our analysis to the Western Palearctic (sensu Snow \& Perrins, 1998). We thus excluded B. $o$. harterti for poor data availability, and the two Macaronesian subspecies (B. o. distincus, B. o. insularum), as these show distinctive responses to the environment, being genetically different (Mori et al., 2017), and have a distribution restricted to small oceanic islands (Vaughan \& Vaughan-Jennings, 2005).

As spatial resolution, we considered as appropriate the finest grain available based on future LULC scenarios (i.e. 5.5x5.5 km grid cells; Chen et al., 2020) as this cell size approximates the breeding home-range of the species (Caccamo et al., 2011; Hawkes et al., 2021), thereby representing a biologically meaningful scale.

9 Species occurrences

20 We used occurrences for the breeding season (May-July; Vaughan \& Vaughan-Jennings, 2005) for the period 1992-2016 retrieving data from eBird, Global Biodiversity Information Facility (GBIF), ornitho.it, ornitho.cat and xeno-canto.org as in previous SDM studies (Avalos \& Hernández, 2015; Coxen et al., 2017; Engelhardt, Neuschulz, \& Hof, 2020; Ramellini et al., 2020). We also included survey data from the British Trust for Ornithology (in agreement with BTO's data policy), data for Greece from the Ornithotopos database and 
1 the second European Breeding Bird Atlas (hereafter EBBA) and 2x2 km surveys in Greece

2 (in formal agreement with the Hellenic Ornithological Society), data for the Deux-Sèvres

3 department from the Nature79 database provided by Alexis Martineau. For Northern Italy,

4 the dataset was integrated with nest points opportunistically collected by Dimitri Giunchi in

5 the period 2012-2018.

6 We used data with a maximum positional uncertainty of $5.5 \mathrm{~km}$ to fit the resolution of

7 predictors (Guisan, Thuiller, \& Zimmermann, 2017), retaining the first occurrence in

8 chronological order (i.e. the one reported in the first year available for the cell) when more

9 than one point occurred in the same cell. We cut observations on the species' range to

10 exclude vagrant individuals in non-breeding areas, developing a range shapefile (see Fig. 1)

11 based on the BirdLife species distribution dataset

12 (http://datazone.birdlife.org/species/requestdis), the EBBA1 (Hagemeijer \& Blair, 1997) and

13 the EBBA2 (Keller et al., 2020). We then applied a spatial filtering of the data to reduce

14 spatial autocorrelation (Kramer-Schadt et al., 2013), using the R package 'spThin' (v. 0.2.0;

15 Aiello-Lammens et al., 2015) with a minimum distance of $5.5 \mathrm{~km}$ between points. The final

16 dataset comprised 1628 presences (Fig. 1).

18 Species distribution models

19 Contrasting results on the performance of different SDM algorithms have been reported (e.g.

20 Qiao et al., 2015; Norberg et al., 2019). Therefore, we carried out preliminary tests to

21 compare single-algorithm approaches and ensemble forecasting (i.e. a set of SDM algorithms

22 combined to account for inter-model variability; Araújo \& New, 2007). We then compared

23 standard SDMs (hereafter static SDMs; Milanesi et al., 2020a) to dynamic SDMs. The first

24 relate temporally dynamic occurrences to static predictor variables (e.g. 30-year climate

25 averages), yielding potentially biased estimations of species-environment relationships 
1 (Milanesi et al., 2020a), whereas the latter combine occurrences with time-specific raster

2 values (Reside et al., 2010; Milanesi et al., 2020a). We therefore tested whether the stone-

3 curlew's distribution is driven by long-term or short-term environmental conditions

4 comparing static and dynamic SDMs. In summary, we developed and compared four classes

5 of models:

6 (i) single static SDMs: seven algorithms were developed (see Table S1 for a list of the 7 employed techniques), using static variables (see Environmental variables);

8 (ii) ensemble SDMs: the single static SDMs were combined according to the mean and the

9 weighted average (Marmion et al., 2009). In the weighted average method, the AUCtest (see

10 Evaluation methods) was used to weight model contribution to the final prediction. Static

11 variables were employed;

12 (iii) single dynamic SDMs: seven algorithms (Table S1) were employed, using dynamic

13 variables (see Environmental variables);

14 (iv) ensemble dynamic SDMs: the single dynamic SDMs were combined according to the 15 mean and the weighted average, using dynamic variables.

16 All models were developed in the 'biomod2' (v. 3.3-7) R package (Thuiller et al., 2016).

18 Pseudo-absence selection

19 We generated a set of pseudo-absence points (i.e. surrogates of true absences; Barbet-Massin 20 et al., 2012), also using them as background points for Maxent. Pseudo-absences are often 21 drawn at random in the study area, whereas occurrences typically show a spatial bias.

22 Therefore, models could discriminate between the environmental features of sampled and 23 unsampled areas, rather than between those of suitable and unsuitable areas (Phillips et al., 24 2009). To avoid this problem, Phillips et al. (2009) proposed the 'target-group' method, 25 where pseudo-absences consist of other species' data collected with the same methods used 
1 for the focal species. We used an approach similar to the observer-oriented one (Milanesi,

2 Mori, \& Menchetti, 2020). We considered as our pseudo-absences GBIF data of other bird

3 species recorded by the same observers of the presence data, assuming they were collected

4 with the same sampling bias. However, this approach could only be implemented on the

5 GBIF data, and some biases might still arise. Therefore, we developed an alternative

6 approach and refer to it as the 'Kernel density approach'. We generated a large number of

7 pseudo-absences, weighting their spatial distribution according to a fixed kernel density

8 estimated on all the presence points, by means of the 'adehabitatHR' (v. 0.4.18) R package

9 (Calenge, 2006). We used the ad hoc method for the estimation of the smoothing parameter

10 (Worton, 1989). The procedure was independently repeated on the occurrences separated by

11 year for the period 1992-2016. For both pseudo-absence selection methods, if a cell contained

12 more than one record, the chronologically oldest was retained in the dataset. Finally, we

13 removed pseudo-absences outside the study area and randomly sampled them to obtain a 0.1

14 prevalence (i.e. the ratio between presences and pseudo-absences ensuring an optimal

15 performance; Barbet-Massin et al., 2012). To identify the best pseudo-absence method, we

16 developed and evaluated a set of Maxent models for each method, using static variables (see

17 Environmental variables). We expected the kernel density approach to outperform the target-

18 group method, as the former might be more effective at cancelling out the potential spatial

19 bias in the presence dataset.

\section{Environmental variables}

22 We followed a two-step variable selection procedure, involving first an expert-based pre-

23 selection and then a reduction of multicollinearity. In the first step, we used an expert-based

24 approach (Santini et al., 2021) to derive 17 biologically meaningful environmental predictors

25 (Table 1). We describe the biological rationale supporting expert-based variable choice and 
1 the process of variable preparation in the Appendix S1. For static SDMs, we averaged

2 variables between the years 1973-2013 (climatic and 'prey suitability' variables) and 1992-

32016 (LULC variables). Collectively, we refer to these variables as static variables. For

4 dynamic SDMs, we associated occurrence/pseudo-absence pixels with year-specific values

5 for a given variable (Milanesi et al., 2020a). We refer to these variables as dynamic variables.

6 In the second step, we calculated the Variance Inflation Factor (VIF) to address

7 multicollinearity between predictors. We used the vifstep function in the 'usdm' $\mathrm{R}$ package

8 (v. 1.1-18; Naimi, 2013), using a threshold of three (Zuur, Ieno, \& Elphick, 2010). We

9 reported the initial and final VIF values for static and dynamic variables in Table 1.

10 According to this analysis, the precipitation of the warmest quarter was only retained in the

11 dynamic variable set and the temperature of the warmest quarter only in the static variable

12 set. We excluded precipitation of the warmest quarter, retaining temperature of the warmest

13 quarter for both static and dynamic variable sets. In the end, 13 variables were used in the 14 models (Table 1).

$16 \quad$ Future variables

17 Future projections of bioclimatic conditions were obtained from four Intergovernmental

18 Panel on Climate Change (IPCC) General Circulation Models (GCMs) that gained the 19 minimum score in interdependence (Sanderson, Knutti, \& Caldwell, 2015): ACCESS1-3, 20 CESM1-BGC, CMCC-CM and MIROC5. We considered two emission scenarios 21 corresponding to the IPCC's Representative Concentration Pathways 4.5 and 8.5 (RCP 4.5 and RCP 8.5) for the years 2030, 2050, 2070 and 2090. Bioclimatic variables for every

23 GCMxRCP combination and time interval were produced from the climatic variables 24 available in the CHELSA CMIP-5 timeseries (Karger et al., 2017). Future LULC scenarios 25 were retrieved from Chen et al., 2020. To create a LULC dataset consistent with bioclimatic 
1 scenarios, we selected LULC projections for the MIROC general circulation model (the

2 remaining GCMs used for bioclimatic variables were not available), under RCP 4.5 and 8.5

3 and the Shared Socioeconomic Pathway 5, for 2030, 2050, 2070 and 2090. In future LULC

4 scenarios, urban cover was kept at its 2016 value, due to the extremely low correspondence

5 between the two LULC datasets.

6

$7 \quad$ Model evaluation

8 We evaluated models based on the block cross-validation procedure implemented in the

9 'ENMeval' (v. 0.3.1) R package (Muscarella et al., 2014). In this procedure, data are

10 partitioned into four geographically independent bins; four models are then produced, with

11 three bins used for training and the remaining one used for testing. We used as performance

12 statistics the area under the curve (AUC; Fielding \& Bell, 1997) of the receiver operating

13 characteristic plot, and the Continuous Boyce Index (CBI; Boyce et al., 2002). The AUC

14 metric was computed with the R package 'biomod2' (v. 3.3-7, Thuiller et al., 2016); the CBI

15 with the 'ecospat' (v. 3.1) R package (Di Cola et al., 2017). To detect overfitting in our

16 models, we computed the difference between AUCtest and AUCtrain (AUCdiff;

17 Radosavljevic \& Anderson, 2014). In case of contrasting indications between AUCtest and

$18 \mathrm{CBI}$, we gave priority to the latter, as the usefulness of AUC in SDM has been questioned

19 (Lobo, Jiménez-Valverde, \& Real, 2008).

20 We evaluated variable importance using a model-independent approach (Thuiller et al., 2009)

21 and expressed it as percentage. We then produced the response curves for each model using

22 the evaluation strip method (Elith et al., 2005). To check the ecological validity of the

23 models, we used an expert-based evaluation (Perennes et al., 2021). We defined two

24 subjective scores: (i) Quality of Spatial Prediction (QSP) and (ii) Plausibility of Response

25 Curve (PRC). The QSP was evaluated comparing qualitatively the spatial output of each 
model with the species' distribution in the EBBA1 and EBBA 2 (Hagemeijer \& Blair, 1997;

2 Keller et al., 2020) and with the modelled distribution in the EBBA 2 (Keller et al., 2020).

3 The PRC was evaluated based on the agreement between current knowledge on the species'

4 ecological preferences and the model's response curves for the four variables with the highest

5 percentage contribution. Both scores had three possible values (zero, one, two), with higher

6 values indicating a better performance. Values were jointly discussed and assigned by Andrea

$7 \quad$ Simoncini and Samuele Ramellini.

\section{$9 \quad$ Projections}

10 The models developed during the model-selection phase were either projected on the static

11 variables (static SDMs) or on variables representing the year 2016 (dynamic SDMs). The

12 year 2016 was selected to describe current conditions as it was the closest year to the present

13 time represented in our climatic dataset. The selected model was then projected to future 14 conditions. We initially used a static LULC (i.e. the 2016 LULC variables) in future

15 predictions to constrain climatic outputs (Pang, De Alban, \& Webb, 2021). We then

16 performed an additional analysis projecting models calibrated with the same historical LULC

17 database on scenarios from the future dynamic LULC database (Chen et al., 2020). However,

18 the difference between LULC databases did not allow quantitative interpretations of mean

19 breeding suitability change.

20 In static LULC projections, for each RCP scenario and time interval we developed four

21 projections (one per each GCM) averaging them in a final projection representing breeding

22 habitat suitability for the species. We also computed the standard deviation between the four

23 projections to account for the uncertainty arising from different climatic scenarios

24 (Beaumont, Hughes, \& Pitman, 2008; Porfirio et al., 2014). In dynamic LULC projections, 25 we developed a single projection for each RCP and time interval, under the Shared 
1 Socioeconomic Pathway (SSP) 5 and the MIROC circulation model (other GCMs were not

2 available).

3 When projected to new time periods, SDMs might encounter environmental conditions that

4 are not found in the calibration area (Elith, Kearney, \& Phillips, 2010; Zurell, Elith, \&

5 Schröder, 2012), producing spurious predictions (Owens et al., 2013). This occurs when: (i) a

6 variable is outside the range found when training (i.e. strict extrapolation; Elith et al., 2010),

7 or (ii) each variable is within the calibration range, but the combination of predictors is new

8 (i.e. combinational extrapolation; Zurell et al., 2012). We thus used the environmental

9 overlap mask (Zurell et al., 2012) to identify the areas where extrapolation occurs. We used

10 the 'mecofun' (v. 0.1.0.9000) R package, with one bin per variable for strict extrapolation

11 and five bins per variable to include combinational extrapolation (Zurell et al., 2012).

13 Cell-wise change of habitat suitability

14 To describe the dynamics of breeding habitat suitability for the stone-curlew, we computed

15 the difference of breeding suitability between consecutive time periods for each cell.

16 Therefore, we obtained a set of rasters describing the magnitude of breeding habitat

17 suitability change through consecutive time intervals, accounting for different RCPs and

18 LULC scenarios.

\section{Change of mean habitat suitability}

21 We evaluated the variation of breeding habitat suitability calculating the mean breeding

22 habitat suitability (among all raster cells) for each future projection and considered its

23 percentage change between two consecutive time periods, according to: each GCM under

24 RCP 4.5 and RCP 8.5, and each RCP using the mean of all GCMs. This analysis was carried 25 out for the static LULC projections only. 


\section{Critical areas for conservation}

3 Areas predicted as suitable under both current and future conditions are fundamental to plan

4 in situ conservation actions (Estrada et al., 2016; Thuiller et al., 2019). We binarized each

5 habitat suitability map according to the threshold that maximizes the sum of specificity and

6 sensitivity (Liu, Newell, \& White, 2016). Then, we summed all binarized projections and

$7 \quad$ attributed a score of one if the cell was suitable in all the projections and a score of zero to all

8 other cells. Additionally, we calculated the percentage of currently suitable cells representing

9 critical areas.

11 Further details on the modelling procedure and workflow are reported in the Overview, Data,

12 Model, Assessment and Prediction (ODMAP) protocol (Zurell et al., 2020; Appendix S1).

\section{RESULTS}

\section{Pseudo-absence methods}

17 The mean AUCtest, AUCdiff and CBI did not show marked differences between the two

18 pseudo-absence methods (Table 2). However, except for the fourth run, the CBI was

19 consistently higher for the kernel density approach, which also provided higher quality spatial

20 predictions (Table 2, Fig. S1.2). Therefore, we decided to use the kernel density approach for

21 subsequent analyses. We selected the first run due to the particularly high CBI, a fair

22 AUCtest and a high-quality spatial prediction (Table 2).

23 Dynamic models gained consistently higher CBI and generally higher QSP and PRC than

24 static models (Table 3). Ensemble SDMs showed high AUCtest, but not significantly higher

25 than the best-performing single methods (i.e. Random Forest, Maxent, GLM), and a discrete 
1 overfitting (Table 3). The CBI and PRC showed the same general pattern, with higher

2 estimates for dynamic ensemble models (Table 3). Spatial predictions did not differ

3 significantly between static and dynamic models, except for the ANN algorithm (Fig. S1.3-

4 S1.4). However, static models identified suitable areas at the southern edge of the study area

5 in the African continent where the species is absent (Keller et al., 2020). Instead, we found a

6 higher agreement in these areas between dynamic models' projections and the actual species'

7 range (Fig. S1.3-S1.4). Ensemble models gained good quality spatial outputs but tended to

8 over-predict habitat suitability at high latitudes (e.g. in Arctic Russia, where the species is not

9 found) and under-predict at lower latitudes (e.g. in France and the Iberian Peninsula, where

10 the species is widespread). Instead, GAM and Maxent provided excellent projections in these

11 areas (Fig. S1.3-S1.4). Therefore, we retained the best performing single dynamic model (i.e.

12 Maxent; Fig. 2), that showed a good AUC (0.803), an excellent CBI (0.999) and maximum

13 QSP and PRC values (Table 3).

\section{Future projections}

16 Projections of future breeding habitat suitability for the species differed between static and 17 dynamic LULC scenarios, but not between RCPs and time periods (Fig. S1.5). Dynamic

18 LULC projections described a similar spatial distribution of suitable areas for the species 19 compared to static LULC projections, but with higher suitability estimates (Fig. S1.5). The 20 agreement between GCMs for static LULC projections was mostly high (Fig. S1.7). Strict 21 extrapolation was generally low (Fig. S1.8-S1.9, Fig. S1.12), although it occurred consistently in some regions at the margins of our study area (e.g. Northern Russia) and it

23 was generally higher under RCP 8.5. Combinational extrapolation was far more extensive 24 and showed increasing values with latitude and under RCP 8.5 (Fig. S1.10-S1.12). 
1 Cell-wise change of habitat suitability

2 The cell-wise change of habitat suitability was particularly evident in the first time interval

3 (i.e. 2016-2030), while quite small in the subsequent ones (Fig. 3). Suitable areas for the

$4 \quad$ species are expected to shift northwards. Broad areas in the central-southern part of the range

5 are predicted to be lost, most of them in the time interval 2016-2030. Differences between

6 static and dynamic LULC are marked, with the suitability of the latter predicted to undergo a

7 higher change (Fig. 3).

8

\section{Change of mean habitat suitability}

10 The mean breeding habitat suitability considering a static LULC is predicted to remain stable

11 in all time intervals and for most GCMs (Fig. S1.6A and S1.6B). However, when comparing

12 the predictions for different GCMs, the differences were quite marked. The RCP had also a

13 significant effect, as the percentages under RCP 8.5 were remarkably higher (Fig. S1.6C).

\section{Critical areas for conservation}

16 France, South-Eastern UK, Northern Italy and Israel were the regions with the highest

17 proportion of conservation critical areas (Fig. 4). The percentage of currently suitable areas

18 predicted to remain suitable was relatively low $(27.47 \%)$.

\section{DISCUSSION}

22 Relying on 1628 occurrences of the stone-curlew, we developed a robust species distribution

23 modelling framework for the species, based on a Maxent model built with year-specific

24 variables and calibrated using a kernel density approach for the pseudo-absences. Our model

25 predicted significant short-term changes in the spatial distribution of suitable areas for the 
1 species and allowed the identification of areas critical for its conservation under global

2 change. Furthermore, our results suggested that the distribution of the stone-curlew might be

3 affected by short-term conditions, rather than long-term ones, and confirmed that broad areas

4 of the Western Palearctic are likely to be suitable for the species in the future.

5 The northern shift of suitable areas predicted by our model is consistent with our hypothesis,

6 with the projection for the species (Huntley et al., 2007), and with projections for other

7 pseudo-steppic species (e.g. the Great Bustard Otis tarda and Little Bustard Tetrax tetrax in

8 Estrada et al., 2016 and the European Roller Coracias garrulus in Kiss et al., 2020). The loss

9 of suitable areas in the Mediterranean region is not surprising as the Mediterranean

10 biogeographical region represents a hotspot of global change, and extensive biodiversity

11 losses have been predicted (Sala et al., 2000).

12 Even if strong variations between GCMs and RCPs in the expected trajectories of mean

13 breeding habitat suitability for the stone-curlew may hinder sound conclusions, the predicted

14 gains and losses of mean habitat suitability were balanced, suggesting a stable mean habitat

15 suitability for the species through time. This agrees with our expectation that mean habitat

16 suitability for the species would remain stable or increase, as global warming is milder in

17 warm temperate areas (IPCC, 2013) and might therefore have a limited impact on mean

18 habitat suitability. Dispersal ability, biotic interactions and the carrying capacity of suitable

19 habitats might determine whether a stable mean habitat suitability translates into a stable

20 population size (Bateman et al., 2013; Holloway, Miller, \& Gillings, 2016).

21 Habitat suitability has been linked to population size and trends in birds (Green et al., 2008;

22 Stiels et al., 2021). We showed that large areas of the study region are predicted as suitable in

23 the future, and that a stable mean habitat suitability is likely. Hence, according to our

24 forecasts, the species may be able to maintain viable populations in the Western Palearctic.

25 However, given the relatively low percentage of areas suitable under both current and future 
1 conditions and the predicted shift of suitable areas, the species might need to track its niche in

2 the future. Evidence of the ability of animals to track their niche is contrasting (Devictor et

3 al., 2008; Chen et al., 2011) and many terrestrial organisms have been shown to shift their

4 distribution at a sufficient pace to track recent temperature changes (Chen et al., 2011).

5 Species affected by global change may also persist under unfavourable conditions being

6 phenotypically plastic and becoming locally adapted (Valladares et al., 2014). Moreover,

7 biological interactions and movement/dispersal constraints might prevent them from

8 colonizing newly suitable areas (Bateman et al., 2013; Holloway, Miller, \& Gillings, 2016).

9 Our results point toward a critical use of the target-group pseudo-absence method, and we

10 recommend its explicit testing especially when using multi-source citizen science datasets.

11 Our results did not evidence a better performance for ensemble methods, contrary to other

12 studies (e.g. Marmion et al., 2009), and support a tailor-made choice of the modelling

13 method. Dynamic models performed better than static ones (Table 3) as expected, supporting

14 previous works explicitly testing the two approaches (e.g. Reside et al., 2010; Milanesi et al.,

15 2020a). Due to its minimal contribution to the final model, the 'prey suitability' variable (Fig.

16 S1.1) probably failed to describe the real patterns of habitat suitability for the stone-curlew's

17 preys (Table 1). This might depend on the exclusion of relevant prey items, as the species

18 exploits a wide spectrum of food items (Vaughan \& Vaughan-Jennings, 2005) that is difficult

19 to model through SDMs. We nevertheless highlight the importance of considering biotic

20 predictors though suggest including the entire trophic web of a species.

21 Correlative species distribution models assume an equilibrium condition between the species

22 and the environment (Araújo \& Pearson, 2005). Areas that have been abandoned by the

23 stone-curlew during the last decades of the past century can be recolonized, as happened in

24 the UK following the targeted conservation efforts of the LIFE11INF/UK000418 'Securing

25 the future of the stone-curlew throughout its range in the UK'. This suggests that suitable 
1 climate and LULC conditions at the relatively coarse scale of our study exist in those areas.

2 Therefore, the SDMs' equilibrium assumption for this species might be violated and future

3 studies could explicitly account for non-equilibrium conditions (Václavík \& Meentemeyer,

4 2012). SDMs also assume the evolutionary conservatism of the species' ecological niche

5 through time (Peterson, Soberón, \& Sanchez-Cordero, 1999; Barbet-Massin et al., 2011), a

6 condition that is difficult to prove and deserves specific attention. Thanks to constant

7 improvements in climate and LULC scenarios, in the future our workflow could be applied to

8 a wider spectrum of scenarios, to better represent all the components of uncertainty (Thuiller

9 et al., 2019). However, the two RCPs employed in our study can provide valuable insights on

10 the effect of global change on habitat suitability, as demonstrated by their extensive use (e.g.

11 Kiss et al., 2020; Stiels et al., 2021). We also limited our study to the breeding period:

12 understanding the drivers and changes of habitat suitability for the stone-curlew across

13 migratory and wintering grounds might provide further insights for its conservation.

15 The stone-curlew is philopatric in the breeding areas (Green, 1990) and this might delay

16 habitat-tracking under environmental change. Considering this latter scenario, critical areas

17 might act as a stronghold for the species, and anticipatory conservation efforts should

18 primarily focus on these areas (Thuiller et al., 2019). Furthermore, ensuring high connectivity

19 conditions for the species in areas predicted to become unsuitable might contribute to

20 maintain viable populations and facilitate niche tracking (Heller \& Zavaleta, 2009). Indeed,

21 habitat fragmentation contributed to the species' decline in the '90s (Tucker \& Evans, 1997).

22 Finally, enhanced monitoring efforts in areas predicted to become suitable might increase

23 early-detection probability and mitigate the negative effects of biotic interactions. Our model

24 evidenced the importance of two LULC classes that are heavily affected by farming and

25 harvesting activities (i.e. non-irrigated agricultural areas and grasslands). Precisely, the most 
1 critical areas and the areas predicted to become suitable for the stone-curlew are in

2 intensively cultivated areas, corresponding to the 'core of EU continental agriculture'

3 (D'Amico et al., 2013), England and the Po Plain. Furthermore, in France, the country

4 hosting the largest portion of critical areas, over $60 \%$ of breeding pairs are found in the

5 Central/Western region within arable crops (Malvaud, 1996; Issa \& Muller, 2015). In these

6 ecosystems, ad hoc management interventions on a local scale can be effectively used to

7 favour stone-curlew's presence (Hawkes et al., 2021).

8 In conclusion, our study refines current knowledge on the effects of global change for the

9 stone-curlew, providing predictions of breeding habitat suitability for the species at high

10 temporal and spatial resolutions, and conservation planners might benefit from our results by

11 incorporating indications on the most relevant conservation areas in the development of

12 action plans for the species. 


\section{ACKNOWLEDGMENTS}

2

3 We thank Chris Vernon, Diego Rubolini, Luca Forneris and Min Chen for technical help,

4 Danae Portolou and Nikos Tsiopelas for providing aggregated occurrence data. We also

5 thank Saverio Gatto for granting us the permission to use his stone-curlew's photograph.

6 


\section{DATA ACCESSIBILITY STATEMENT}

3 Presence data used to develop species distribution models for the Eurasian stone-curlew are

4 available at: https://doi.org/10.6084/m9.figshare.16727296.v1

5 Longitude, latitude and year are reported for each observation. Data from the British Trust for

6 Ornithology are omitted in agreement with the data access policy. Data from ornitho.it are

7 accompanied by a citation, in compliance with the site's rules. 


\section{REFERENCES}

3 Aiello-Lammens, M. E., Boria, R. A., Radosavljevic, A., Vilela, B., \& Anderson, R. P. (2015). spThin: An R package for spatial thinning of species occurrence records for use in ecological niche models. Ecography 38, 541-545.

6 Araújo, M. B., \& Pearson, R. G. (2005). Equilibrium of species’ distributions with climate. Ecography 28, 693-695.

8 Araújo, M. B., \& New, M. (2007). Ensemble forecasting of species distributions. Trends Ecol. Evol. 22, 42-47.

Avalos, V. del R., \& Hernández, J. (2015). Projected distribution shifts and protected area coverage of range-restricted Andean birds under climate change. Glob. Ecol. Conserv. 4, 459-469.

Barbet-Massin, M., Thuiller, W., \& Jiguet, F. (2011). The fate of European breeding birds under climate, land-use and dispersal scenarios. Glob. Chang. Biol. 18, 881-890.

Barbet-Massin, M., Jiguet, F., Albert, C. H., \& Thuiller, W. (2012). Selecting pseudoabsences for species distribution models: How, where and how many? Methods Ecol. Evol. 3, 327-338.

Bateman, B. L., Murphy, H. T., Reside, A. E., Mokany, K., \& Vanderwal, J. (2013). Appropriateness of full-, partial- and no-dispersal scenarios in climate change impact

Beaumont, L. J., Hughes, L., \& Pitman, A. J. (2008). Why is the choice of future climate scenarios for species distribution modelling important? Ecol. Lett. 11, 1135-1146.

BirdLife International. (2017). European birds of conservation concern: populations, trends and national responsibilities. Cambridge: BirdLife International.

25 BirdLife International. (2018). Burhinus oedicnemus. The IUCN Red List of Threatened 
1 species.

2 BirdLife International. (2021). Species factsheet: Burhinus oedicnemus.

3 Boyce, S. M., Vernier, R., Nielsen, E., \& Schmiegelow, A. F. K. (2002). Evaluating resource selection functions. Ecol. Model. 157, 281-300.

5 Burfield, I. (2005). The conservation status of steppic birds in Europe. In Ecology and 6 Conservation of Steppe-Land Birds. Bota, G., Morales, M., Mañosa, S. \& Camprodon, J. $7 \quad$ (Eds.), Barcelona: Lynx Edicions \& Centre Tecnològic Forestal de Catalunya.

8 Caccamo, C., Pollonara, E., Emilio Baldaccini, N., \& Giunchi, D. (2011). Diurnal and 9 nocturnal ranging behaviour of Stone-curlews Burhinus oedicnemus nesting in river 10 habitat. Ibis $153,707-720$.

11 Calenge, C. (2006). The package "adehabitat" for the R software: A tool for the analysis of 12 space and habitat use by animals. Ecol. Model. 197, 516-519.

13 Caro, T. M. (2010). Conservation by proxy: indicator, umbrella, keystone, flagship, and other surrogate species. Washington: Island Press.

15 Chen, I.-C., Hill, J. K., Ohlemuller, R., Roy, D. B., \& Thomas, C. D. (2011). Rapid Range 16 Shifts of Species Associated with High Levels of Climate Warming. Science 333, 1024$17 \quad 1026$.

18 Chen, M., Vernon, C. R., Graham, N. T., Hejazi, M., Huang, M., Cheng, Y., \& Calvin, K. 19 (2020). Global land use for $2015-2100$ at $0.05^{\circ}$ resolution under diverse socioeconomic and climate scenarios. Sci. Data 7, 1-11.

21 Coxen, C. L., Frey, J. K., Carleton, S. A., \& Collins, D. P. (2017). Species distribution models for a migratory bird based on citizen science and satellite tracking data. Glob. Ecol. Conserv. 11, 298-311.

24 D’Amico, M., Coppola, A., Chinnici, G., Di Vita, G., \& Pappalardo, G. (2013). Agricultural systems in the European Union: An analysis of regional differences. New Medit. 12, 28 
1

\section{4.}

Devictor, V., Julliard, R., Couvet, D., \& Jiguet, F. (2008). Birds are tracking climate warming, but not fast enough. Proc. R. Soc. B - Biol. Sci. 275, 2743-2748.

Di Cola, V., Broennimann, O., Petitpierre, B., Breiner, F. T., D’Amen, M., Randin, C., Engler, R., Pottier, J., Pio, D., Dubuis, A., Pellissier, L., Mateo, R. G., Hordijk, W., Salamin, N., \& Guisan, A. (2017). ecospat: an R package to support spatial analyses and modeling of species niches and distributions. Ecography 40, 774-787.

Elith, J., Ferrier, S., Huettmann, F., \& Leathwick, J. (2005). The evaluation strip: A new and robust method for plotting predicted responses from species distribution models. Ecol. Model. 186, 280-289.

Elith, J., Kearney, M., \& Phillips, S. (2010). The art of modelling range-shifting species. Methods Ecol. Evol. 1, 330-342.

Engelhardt, E. K., Neuschulz, E. L., \& Hof, C. (2020). Ignoring biotic interactions overestimates climate change effects: The potential response of the spotted nutcracker to changes in climate and resource plants. J. Biogeogr. 47, 143-154.

Estrada, A., Delgado, M. P., Arroyo, B., Traba, J., \& Morales, M. B. (2016). Forecasting large-scale habitat suitability of european bustards under climate change: The role of environmental and geographic variables. PLoS One 11, 1-17.

Fielding, A., \& Bell, J. F. (1997). A review of methods for the assessment of prediction errors in conservation presence/absence models. Environ. Conserv. 24, 38-49.

Gaget, E., Fay, R., Augiron, S., Villers, A., \& Bretagnolle, V. (2019). Long-term decline despite conservation efforts questions Eurasian Stone-curlew population viability in intensive farmlands. Ibis 161, 359-371.

Green, R. E. (1990). Saving the stone curlew. Sanctuary Bullettin 19, 37-39.

Green, R. E., Collingham, Y. C., Willis, S. G., Gregory, R. D., Smith, K. W., \& Huntley, B. 
(2008). Performance of climate envelope models in retrodicting recent changes in bird population size from observed climatic change. Biol. Lett. 4, 599-602.

Guisan, A., \& Zimmermann, N. E. (2000). Predictive habitat distribution models in ecology. Ecol. Model. 135, 147-186.

Guisan, A., Thuiller, W., \& Zimmermann, N. E. (2017). Habitat Suitability and Distribution Models with applications in R. Cambridge: Cambridge University Press.

Hagemeijer, W. J. M., \& Blair, M. J. (1997). The EBCC Atlas of European Breeding Birds: Their Distribution and Abundance. London: T \& A D Poyser.

Hawkes, R., Smart, J., Brown, A., Jones, H., Lane, S., Wells, D., \& Dolman, P. M. (2019). Multi-taxa consequences of management for an avian umbrella species. Biol. Conserv. 236, 192-201.

Hawkes, R. W., Smart, J., Brown, A., Green, R. E., Jones, H., \& Dolman, P. M. (2021). Effects of experimental land management on habitat use by Eurasian Stone-curlews. Anim. Conserv., 1-13.

Heller, N. E., \& Zavaleta, E. S. (2009). Biodiversity management in the face of climate change: A review of 22 years of recommendations. Biol. Conserv. 142, 14-32.

Holloway, P., Miller, J. A., \& Gillings, S. (2016). Incorporating movement in species distribution models: how do simulations of dispersal affect the accuracy and uncertainty of projections? Int. J. Geogr. Inf. Sci. 30, 2050-2074.

Hunter, M., Westgate, M., Barton, P., Calhoun, A., Pierson, J., Tulloch, A., Beger, M., Branquinho, C., Caro, T., Gross, J., Heino, J., Lane, P., Longo, C., Martin, K., McDowell, W. H., Mellin, C., Salo, H., \& Lindenmayer, D. (2016). Two roles for ecological surrogacy: Indicator surrogates and management surrogates. Ecol. Indic. 63, $121-125$.

Huntley, B., Green, R. E., Collingham, Y. C., \& Willis, S. G. (2007). A climatic atlas of 
$1 \quad$ European breeding birds. Barcelona: The RSPB and Lynx Edicions.

2 IPCC. (2013). Climate change 2013: The Physical Science Basis. Contribution of Working

3 Group I to the Fifth Assessment Report of the Intergovernmental Panel on Climate

$4 \quad$ Change. Cambridge: Cambridge University Press.

5 Issa, N., \& Muller, Y. (2015). Atlas des oiseaux de France metropolitaine; nidification et $6 \quad$ presence hivernale. Paris: Delachaux \& Niestle.

7 Karger, D. N., Conrad, O., Böhner, J., Kawohl, T., Kreft, H., Soria-Auza, R. W., 8 Zimmermann, N. E., Linder, H. P., \& Kessler, M. (2017). Climatologies at high 9 resolution for the earth's land surface areas. Sci. Data 4, 1-20.

10 Keller, V., Herrando, S., Voří̌sek, P., Franch, M., Kipson, M., Milanesi, P., Martí, D., Anton, 11 M., Klvaňová, A., Kalyakin, M. V., Bauer, H. G., \& Foppen, R. P. B. (2020). European 12 Breeding Bird Atlas 2: Distribution, Abundance and Change. Barcelona: European Bird 13 Census Council \& Lynx Edicions.

14 Kiss, O., Catry, I., Avilés, J. M., Barišić, S., Kuzmenko, T., Cheshmedzhiev, S., Marques, A. 15 T., Meschini, A., Schwartz, T., Tokody, B., \& Végvári, Z. (2020). Past and future 16 climate-driven shifts in the distribution of a warm-adapted bird species, the European Roller Coracias garrulus. Bird Study, 143-159.

18 Kramer-Schadt, S., Niedballa, J., Pilgrim, J. D., Schröder, B., Lindenborn, J., Reinfelder, V., 19 Stillfried, M., Heckmann, I., Scharf, A. K., Augeri, D. M., Cheyne, S. M., Hearn, A. J., Ross, J., Macdonald, D. W., Mathai, J., Eaton, J., Marshall, A. J., Semiadi, G., Rustam, R., Bernard, H., Alfred, R., Samejima, H., Duckworth, J. W., Breitenmoser-Wuersten, C., Belant, J. L., Hofer, H., \& Wilting, A. (2013). The importance of correcting for sampling bias in MaxEnt species distribution models. Divers. Distrib. 19, 1366-1379.

24 Liu, C., Newell, G., \& White, M. (2016). On the selection of thresholds for predicting species occurrence with presence-only data. Ecol. Evol. 6, 337-348. 
1 Lobo, J. M., Jiménez-Valverde, A., \& Real, R. (2008). AUC: A misleading measure of the

2 performance of predictive distribution models. Glob. Ecol. Biogeogr. 17, 145-151.

3 Malvaud, F. (1996). L'Oedicneme criard en France (Burhinus oedicnemus). Caen: Groupe

$4 \quad$ Ornithologique Normand.

5 Marmion, M., Parviainen, M., Luoto, M., Heikkinen, R. K., \& Thuiller, W. (2009).

6 Evaluation of consensus methods in predictive species distribution modelling. Divers.

$7 \quad$ Distrib. 15, 59-69.

8 Mcshea, W. J. (2014). What are the roles of species distribution models in conservation

$9 \quad$ planning? Environ. Conserv. 41, 93-96.

10 Milanesi, P., Della Rocca, F., \& Robinson, R. A. (2020a). Integrating dynamic environmental 11 predictors and species occurrences: Toward true dynamic species distribution models. $12 \quad$ Ecol. Evol. 10, 1087-1092.

13 Milanesi, P., Mori, E., \& Menchetti, M. (2020b). Observer-oriented approach improves species distribution models from citizen science data. Ecol. Evol. 10, 12104-12114.

15 Miller-Rushing, A. J., Primack, R. B., \& Sekercioglu, C. H. (2010). Conservation 16 consequences of climate change for birds. In Effects of Climate Change on Birds: 29517 311. Møller, A.P., Fiedler, W. \& Berthold, P. (Eds.). Oxford: Oxford University Press.

18 Mori, A., Giunchi, D., Rodríguez-Godoy, F., Grasso, R., Baldaccini, N. E., \& Baratti, M. 19 (2017). Multilocus approach reveals an incipient differentiation process in the Stonecurlew, Burhinus oedicnemus around the Mediterranean basin. Conserv. Genet. 18, 197Anderson, R. P. (2014). ENMeval: An R package for conducting spatially independent evaluations and estimating optimal model complexity for Maxent ecological niche models . Methods Ecol. Evol. 5, 1198-1205. 
1 Naimi, B. (2013). usdm: Uncertainty analysis for species distribution models.

2 Norberg, A., Abrego, N., Blanchet, F. G., Adler, F. R., Anderson, B. J., Anttila, J., Araújo,

3 M. B., Dallas, T., Dunson, D., Elith, J., Foster, S. D., Fox, R., Franklin, J., Godsoe, W.,

4 Guisan, A., O’Hara, B., Hill, N. A., Holt, R. D., Hui, F. K. C., Husby, M., Kålås, J. A.,

5 Lehikoinen, A., Luoto, M., Mod, H. K., Newell, G., Renner, I., Roslin, T., Soininen, J.,

6 Thuiller, W., Vanhatalo, J., Warton, D., White, M., Zimmermann, N. E., Gravel, D., \&

7 Ovaskainen, O. (2019). A comprehensive evaluation of predictive performance of 33

8 species distribution models at species and community levels. Ecol. Monogr. 89, 1-24.

9 Onrubia, A., \& Andrés, T. (2005). Impact of human activities on steppic-land birds: a review

10 in the context of the Western Palearctic. In Ecology and Conservation of Steppe-Land

11 Birds. Bota, G., Morales, M., Mañosa, S. \& Camprodon, J. (Eds.). Barcelona: Lynx

12 Edicions \& Centre Tecnològic Forestal de Catalunya.

13 Owens, H. L., Campbell, L. P., Dornak, L. L., Saupe, E. E., Barve, N., Soberón, J., Ingenloff, 14 K., Lira-Noriega, A., Hensz, C. M., Myers, C. E., \& Peterson, A. T. (2013). Constraints

15 on interpretation of ecological niche models by limited environmental ranges on $16 \quad$ calibration areas. Ecol. Model. 263, 10-18.

17 Pang, S. E. H., De Alban, J. D. T., \& Webb, E. L. (2021). Effects of climate change and land 18 cover on the distributions of a critical tree family in the Philippines. Sci. Rep. 11, 1-13.

19 Parmesan, C. (2006). Ecological and evolutionary responses to recent climate change. Annu. 20 Rev. Ecol. Evol. Syst. 37, 637-669.

21 Perennes, M., Diekötter, T., Groß, J., \& Burkhard, B. (2021). A hierarchical framework for 22 mapping pollination ecosystem service potential at the local scale. Ecol. Model. 444.

23 Peterson, A. T., Soberón, J., \& Sanchez-Cordero, V. (1999). Conservatism of Ecological 24 Niches in Evolutionary Time. Science 285, 1265-1267.

25 Phillips, S. J., Dudík, M., Elith, J., Graham, C. H., Lehmann, A., Leathwick, J., \& Ferrier, S. 
(2009). Sample selection bias and presence-only distribution models: Implications for background and pseudo-absence data. Ecol. Appl. 19, 181-197.

Porfirio, L. L., Harris, R. M. B., Lefroy, E. C., Hugh, S., Gould, S. F., Lee, G., Bindoff, N. L., \& Mackey, B. (2014). Improving the use of species distribution models in conservation planning and management under climate change. PLoS One 9, 1-21.

Qiao, H., Soberón, J., \& Peterson, A. T. (2015). No silver bullets in correlative ecological niche modelling: Insights from testing among many potential algorithms for niche estimation. Methods Ecol. Evol. 6, 1126-1136.

Radosavljevic, A., \& Anderson, R. P. (2014). Making better Maxent models of species distributions: Complexity, overfitting and evaluation. J. Biogeogr. 41, 629-643.

Ramellini, S., Simoncini, A., Ficetola, G. F., \& Falaschi, M. (2020). Modelling the potential spread of the Red-billed Leiothrix Leiothrix lutea in Italy. Bird Study 66, 550-560.

Reside, A. E., Vanderwal, J. J., Kutt, A. S., \& Perkins, G. C. (2010). Weather, Not Climate, Defines Distributions of Vagile Bird Species. PLoS One 5, 1-9.

Román-Palacios, C., \& Wiens, J. J. (2020). Recent responses to climate change reveal the drivers of species extinction and survival. Proc. Natl. Acad. Sci. U. S. A. 117, 42114217.

Root, T. L., Price, J. T., Hall, K. R., Schneider, S. H., Rosenzweig, C., \& Pounds, J. A. (2003). Fingerprints of global warming on wild animals and plants. Nature 421, 57-60.

Sala, O. E., Chapin, F. S., Armesto, J. J., Berlow, E., Bloomfield, J., Dirzo, R., HuberSanwald, E., Huenneke, L. F., Jackson, R. B., Kinzig, A., Leemans, R., Lodge, D. M., Mooney, H. A., Oesterheld, M., Poff, N. L. R., Sykes, M. T., Walker, B. H., Walker, M., \& Wall, D. H. (2000). Global biodiversity scenarios for the year 2100. Science 287, 1770-1774.

Sanderson, B. M., Knutti, R., \& Caldwell, P. (2015). A representative democracy to reduce 
1 interdependency in a multimodel ensemble. J. Climate 28, 5171-5194.

2 Santini, L., Benítez-López, A., Maiorano, L., Čengić, M., \& Huijbregts, M. A. J. (2021).

3 Assessing the reliability of species distribution projections in climate change research.

$4 \quad$ Divers. Distrib. 27, 1035-1050.

5 Snow, D., \& Perrins, C. M. (1998). The Birds of the Western Palearctic concise edition.

$6 \quad$ Oxford: Oxford University Press.

7 Stiels, D., Bastian, H. V., Bastian, A., Schidelko, K., \& Engler, J. O. (2021). An iconic messenger of climate change? Predicting the range dynamics of the European Bee-eater (Merops apiaster). J. Ornithol. 162, 631-644.

10 Thuiller, W., Lafourcade, B., Engler, R., \& Araújo, M. B. (2009). BIOMOD - A platform for ensemble forecasting of species distributions. Ecography 32, 369-373.

12 Thuiller, W., Georges, D., Engler, R., \& Breiner, F. (2016). 'biomod2': Ensemble platform 13 for species distribution modeling.

14 Thuiller, W., Guéguen, M., Renaud, J., Karger, D. N., \& Zimmermann, N. E. (2019). 15 Uncertainty in ensembles of global biodiversity scenarios. Nat. Commun. 10, 1-9.

16 Tucker, G. M., \& Evans, M. I. (1997). Habitats for birds in Europe: a conservation strategy 17 for the wider environment. Conservation Series No. 6. Cambridge: BirdLife 18 International.

19 Václavík, T., \& Meentemeyer, R. K. (2012). Equilibrium or not? Modelling potential 20 distribution of invasive species in different stages of invasion. Divers. Distrib. 18, 7383. M., Cornwell, W., Gianoli, E., van Kleunen, M., Naya, D. E., Nicotra, A. B., Poorter, H., \& Zavala, M. A. (2014). The effects of phenotypic plasticity and local adaptation on forecasts of species range shifts under climate change. Ecol. Lett. 17, 1351-1364. 
1 Vanderwal, J., Murphy, H. T., Kutt, A. S., Perkins, G. C., Bateman, B. L., Perry, J. J., \&

2 Reside, A. E. (2013). Focus on poleward shifts in species' distribution underestimates

3 the fingerprint of climate change. Nat. Clim. Chang. 3, 239-243.

4 Vaughan, R., \& Vaughan-Jennings, N. (2005). The Stone-curlew Burhinus oedicnemus.

$5 \quad$ Falmouth: Isabelline Books.

6 Worton, B. J. (1989). Kernel Methods for Estimating the Utilization Distribution in Home-

$7 \quad$ Range Studies. Ecology 70, 164-168.

8 Zurell, D., Elith, J., \& Schröder, B. (2012). Predicting to new environments: Tools for

9 visualizing model behaviour and impacts on mapped distributions. Divers. Distrib. 18, $10 \quad 628-634$.

11 Zurell, D., Franklin, J., König, C., Bouchet, P. J., Dormann, C. F., Elith, J., Fandos, G., Feng, 12 X., Guillera-Arroita, G., Guisan, A., Lahoz-Monfort, J. J., Leitão, P. J., Park, D. S., 13 Peterson, A. T., Rapacciuolo, G., Schmatz, D. R., Schröder, B., Serra-Diaz, J. M., 14 Thuiller, W., Yates, K. L., Zimmermann, N. E., \& Merow, C. (2020). A standard 15 protocol for reporting species distribution models. Ecography 43, 1261-1277.

16 Zuur, A. F., Ieno, E. N., \& Elphick, C. S. (2010). A protocol for data exploration to avoid 17 common statistical problems. Methods Ecol. Evol. 1, 3-14. 
1 Table 1 Candidate environmental variables to calibrate SDMs for the Eurasian stone-curlew.

2 To describe the correlation among variables, we report the VIF (Variance Inflation Factor)

3 for the initial and final sets of static and dynamic variables. Variables included in the

4 dynamic Maxent model used for future projections are shown in bold, and their percentage

5 contribution is reported.

\begin{tabular}{|c|c|c|c|c|c|}
\hline \multirow[t]{2}{*}{ Variable } & \multicolumn{2}{|l|}{ Static } & \multicolumn{2}{|l|}{ Dynamic } & \multirow{2}{*}{ Contribution $(\%)$} \\
\hline & $\mathrm{VIF}_{\text {in }}$ & VIF fin $_{\text {fin }}$ & $\mathrm{VIF}_{\text {in }}$ & VIF fin $_{\text {fin }}$ & \\
\hline $\begin{array}{l}\text { Percentage cover of agricultural } \\
\text { areas (non-irrigated) }\end{array}$ & 3.432 & 1.407 & 5.007 & 2.319 & $27.6 \%$ \\
\hline $\begin{array}{l}\text { Temperature of the warmest } \\
\text { quarter }\end{array}$ & 810.809 & 2.206 & 171.087 & - & $23.9 \%$ \\
\hline Temperature seasonality & 69.530 & 1.773 & 20.111 & 1.207 & $17.4 \%$ \\
\hline Percentage cover of grass & 1.736 & 1.274 & 2.541 & 1.684 & $10.8 \%$ \\
\hline $\begin{array}{l}\text { Percentage cover of agricultural } \\
\text { areas (irrigated) }\end{array}$ & 1.135 & 1.022 & 1.339 & 1.088 & $10.1 \%$ \\
\hline Slope & 1.463 & 1.229 & 1.977 & 1.684 & $9.0 \%$ \\
\hline Percentage cover of trees & 3.948 & 1.955 & 3.532 & 2.318 & $8.7 \%$ \\
\hline Karst area & 1.072 & 1.041 & 1.082 & 1.057 & $6.9 \%$ \\
\hline Distance from water & 2.002 & 1.831 & 1.767 & 1.557 & $4.8 \%$ \\
\hline Percentage cover of urban areas & 1.158 & 1.114 & 1.232 & 1.152 & $4.5 \%$ \\
\hline Precipitation seasonality & 1.747 & 1.607 & 1.823 & 1.722 & $3.6 \%$ \\
\hline Percentage cover of shrubs & 1.428 & 1.216 & 2.039 & 1.345 & $3.0 \%$ \\
\hline Prey suitability & 1.667 & 1.557 & 1.358 & 1.323 & $0.5 \%$ \\
\hline
\end{tabular}


bioRxiv preprint doi: https://doi.org/10.1101/2021.10.04.462847; this version posted October 5, 2021. The copyright holder for this preprint (which was not certified by peer review) is the author/funder, who has granted bioRxiv a license to display the preprint in perpetuity. It is made available under aCC-BY-NC-ND 4.0 International license.

\begin{tabular}{|l|l|l|l|l|l|}
\hline Annual temperature & 1000.396 & - & 142.475 & - & - \\
\hline Annual precipitation & 6.717 & - & 3.686 & - & - \\
\hline $\begin{array}{l}\text { Precipitation of the warmest } \\
\text { quarter }\end{array}$ & 7.323 & - & 3.754 & 2.198 & - \\
\hline $\begin{array}{l}\text { Percentage cover of bare areas } \\
\text { P.983 }\end{array}$ & - & & 6.365 & - & - \\
\hline
\end{tabular}

1

2 
1 Table 2 Evaluation metrics of the static Maxent models for the Eurasian stone-curlew

2 calibrated with two pseudo-absence approaches (target-group and kernel density), for four

3 cross-validation runs. We report Area Under the ROC (Receiver Operating Characteristic)

4 Curve (AUC) of the training and test datasets and their difference; Continuous Boyce Index

5 (CBI); Quality of Spatial Prediction (QSP) and Plausibility of Response Curve (PRC).

6 Quality of Spatial Prediction (QSP) and Plausibility of Response Curve (PRC) are qualitative

7 subjective scores (value of zero, one or two) describing the ecological validity of a model.

8 Mean and standard error are reported for each approach.

9

\begin{tabular}{ccccccc}
\hline \multicolumn{2}{c}{ Target group } & & & & & \\
Run & AUCtrain & AUCtest & AUCdiff & CBI & QSP & PRC \\
1 & 0.891 & 0.679 & 0.212 & 0.852 & 1 & 2 \\
2 & 0.878 & 0.746 & 0.132 & 0.977 & 0 & 2 \\
3 & 0.854 & 0.824 & 0.030 & 0.842 & 1 & 2 \\
4 & 0.850 & 0.832 & 0.018 & 0.654 & 1 & 2
\end{tabular}

Summary
Mean (SE)
$0.868(0.010)$
$0.770(0.036)$
$0.098(0.046) \quad 0.831(0.067)$
$0.75(0.25) \quad 2(0)$

\section{Kernel density}

$\begin{array}{ccccccc}\text { Run } & \text { AUCtrain } & \text { AUCtest } & \text { AUCdiff } & \text { CBI } & \text { QSP } & \text { PRC } \\ 1 & 0.888 & 0.783 & 0.105 & 0.999 & 2 & 1 \\ 2 & 0.884 & 0.871 & 0.013 & 0.985 & 1 & 1 \\ 3 & 0.885 & 0.727 & 0.158 & 0.887 & 2 & 2 \\ 4 & 0.892 & 0.799 & 0.093 & 0.333 & 2 & 2\end{array}$

Summary
Mean (SE)
0.887 (0.002)
$0.795(0.030) \quad 0.092(0.030) \quad 0.801(0.158)$
$1.75(0.25) \quad 1.5(0.29)$ 
1 Table 3 Evaluation metrics of four species distribution modelling strategies for the Eurasian

2 stone-curlew: single static, ensemble static, single dynamic and ensemble dynamic. The

3 following single algorithms have been used: Artificial Neural Networks (ANN),

4 Classification Tree Analysis (CTA), Generalized Additive Models (GAM), Generalized

5 Boosting Models (GBM), Generalized Linear Models (GLM), Maximum entropy (Maxent),

6 Random Forest (RF). The following metrics are reported: Area Under the ROC (Receiver

7 Operating Characteristic) Curve (AUC) of the training and test datasets and their difference;

8 Continuous Boyce Index (CBI). Quality of Spatial Prediction (QSP) and Plausibility of

9 Response Curve (PRC) are subjective scores (value of zero, one or two) describing the

10 ecological validity of a model. The model used for future projections is highlighted in bold.

\begin{tabular}{|c|c|c|c|c|c|c|}
\hline \multicolumn{7}{|c|}{ Single static SDM } \\
\hline Algorithm & AUCtrain & AUCtest & AUCdiff & $C B I$ & $Q S P$ & $P R C$ \\
\hline ANN & 0.608 & 0.595 & 0.013 & 0.160 & 0 & 0 \\
\hline CTA & 0.832 & 0.669 & 0.163 & 0.437 & 0 & 0 \\
\hline GAM & 0.871 & 0.779 & 0.092 & 0.296 & 2 & 2 \\
\hline GBM & 0.896 & 0.785 & 0.111 & 0.517 & 1 & 1 \\
\hline GLM & 0.865 & 0.802 & 0.063 & 0.440 & 0 & 1 \\
\hline Maxent & 0.889 & 0.784 & 0.105 & 0.994 & 2 & 1 \\
\hline $\mathrm{RF}$ & 0.999 & 0.814 & 0.185 & -0.147 & 0 & 1 \\
\hline \multicolumn{7}{|c|}{ Ensemble static SDM } \\
\hline Algorithm & AUCtrain & AUCtest & AUCdiff & $C B I$ & $Q S P$ & $P R C$ \\
\hline Mean & 0.952 & 0.815 & 0.137 & 0.321 & 1 & 1 \\
\hline Weighted & 0.954 & 0.815 & 0.138 & 0.360 & 1 & 1 \\
\hline
\end{tabular}


bioRxiv preprint doi: https://doi org/10.1101/2021.10.04 462847 this version posted October 5,2021 . The copyriaht holder for this preprint (which was not certified by peer review) is the author/funder, who has granted bioRxiv a license to display the preprint in perpetuity. It is made available under aCC-BY-NC-ND 4.0 International license.

\begin{tabular}{ccccccc} 
Algorithm & AUCtrain & AUCtest & AUCdiff & CBI & QSP & PRC \\
ANN & 0.713 & 0.687 & 0.026 & 0.533 & 0 & 0 \\
CTA & 0.758 & 0.634 & 0.123 & 0.675 & 1 & 0 \\
GAM & 0.858 & 0.794 & 0.064 & 0.837 & 2 & 2 \\
GBM & 0.882 & 0.784 & 0.098 & 0.726 & 2 & 1 \\
GLM & 0.851 & 0.793 & 0.058 & 0.471 & 0 & 2 \\
Maxent & $\mathbf{0 . 8 8 5}$ & $\mathbf{0 . 8 0 3}$ & $\mathbf{0 . 0 8 2}$ & $\mathbf{0 . 9 9 9}$ & $\mathbf{2}$ & $\mathbf{2}$ \\
RF & 0.999 & 0.809 & 0.190 & 0.660 & 0 & 1 \\
\hline Ensemble dynamic SDM & & & & 2 \\
Algorithm & AUCtrain & AUCtest & AUCdiff & CBI & QSP & PRC \\
Mean & 0.944 & 0.808 & 0.136 & 0.847 & 1 & 2 \\
Weighted & & 0.946 & 0.810 & 0.136 & 0.870 & 1
\end{tabular}


bioRxiv preprint doi: https://doi.org/10.1101/2021.10.04.462847; this version posted October 5, 2021. The copyright holder for this preprint (which was not certified by peer review) is the author/funder, who has granted bioRxiv a license to display the preprint in perpetuity. It is made available under aCC-BY-NC-ND 4.0 International license.

\section{Figure 1.}

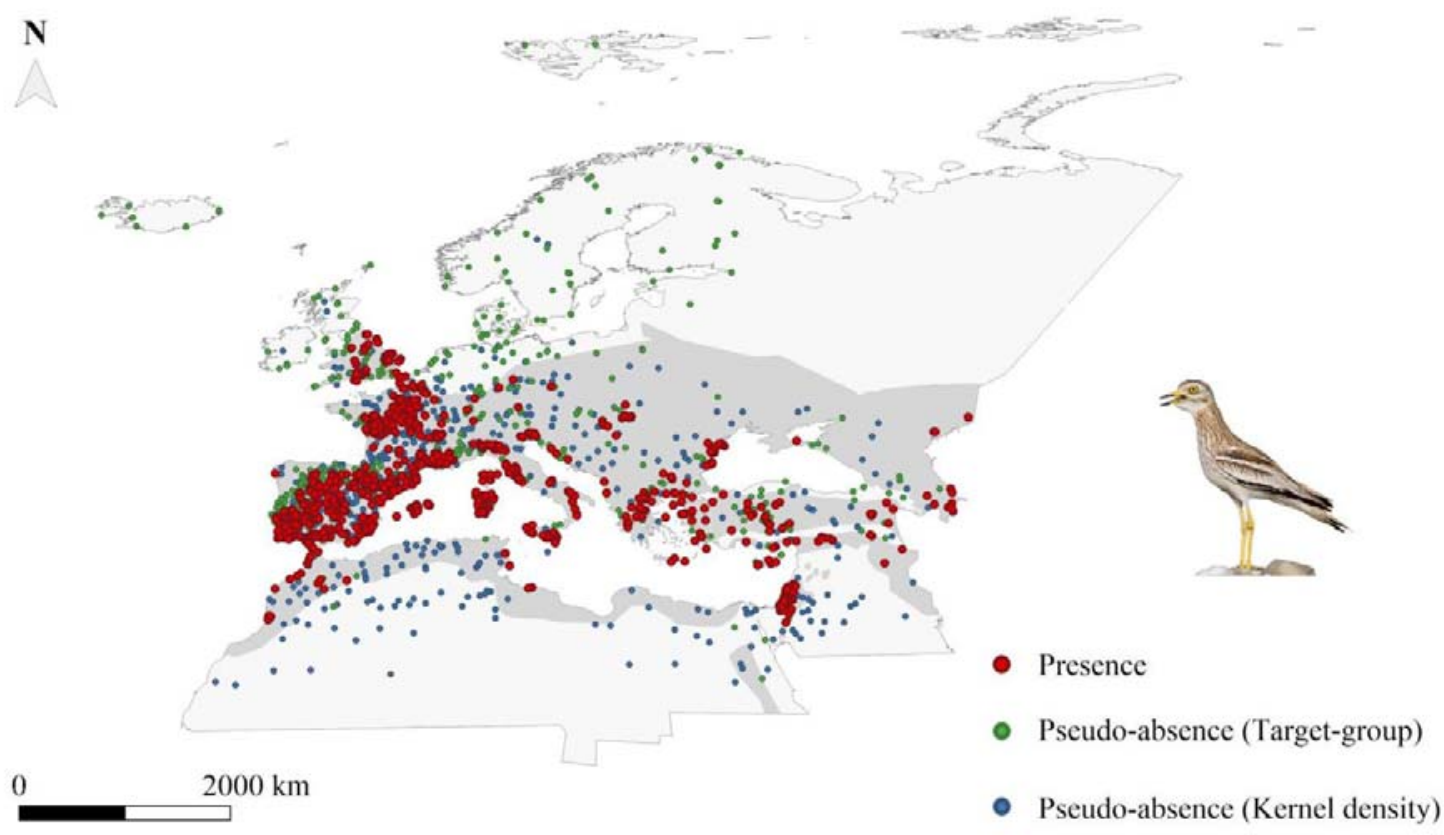


bioRxiv preprint doi: https://doi.org/10.1101/2021.10.04.462847; this version posted October 5, 2021. The copyright holder for this preprint (which was not certified by peer review) is the author/funder, who has granted bioRxiv a license to display the preprint in perpetuity. It is made available under aCC-BY-NC-ND 4.0 International license.

\section{Figure 2.}
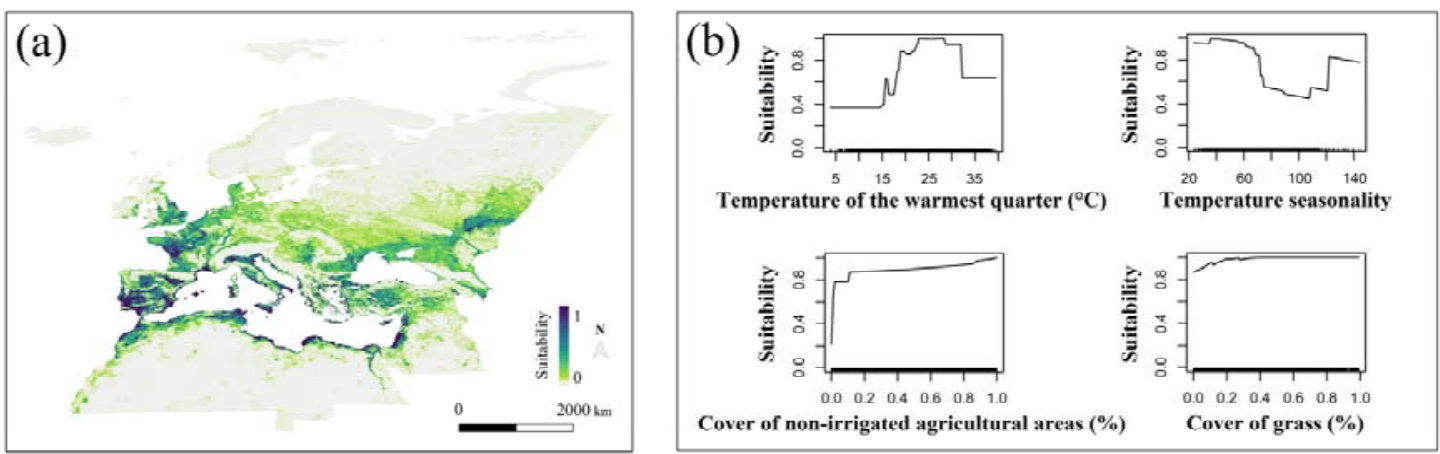

2

3 
bioRxiv preprint doi: https://doi.org/10.1101/2021.10.04.462847; this version posted October 5, 2021. The copyright holder for this preprint (which was not certified by peer review) is the author/funder, who has granted bioRxiv a license to display the preprint in perpetuity. It is made available under aCC-BY-NC-ND 4.0 International license.

\section{Figure 3.}
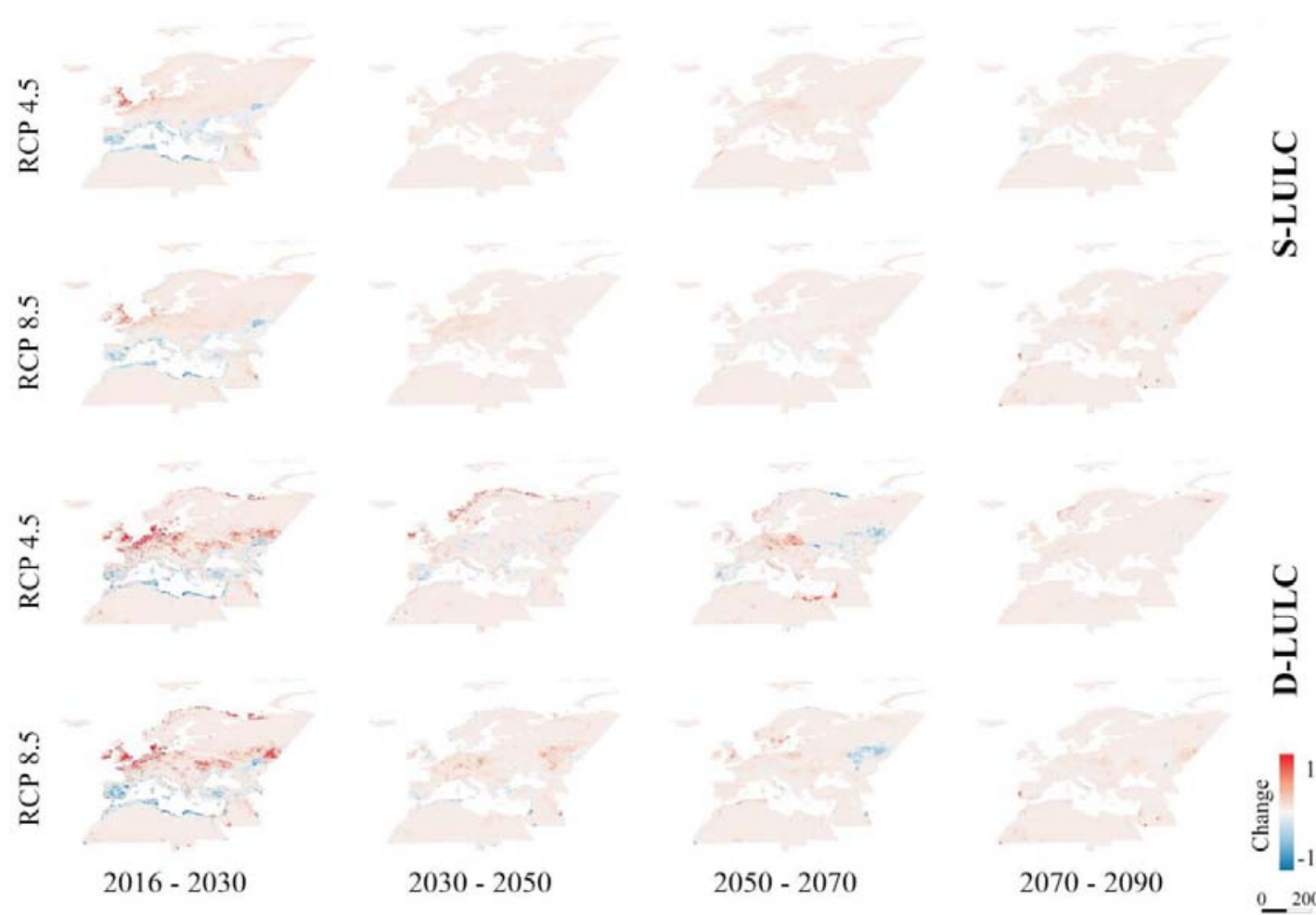

2

3 
bioRxiv preprint doi: https://doi.org/10.1101/2021.10.04.462847; this version posted October 5, 2021. The copyright holder for this preprint (which was not certified by peer review) is the author/funder, who has granted bioRxiv a license to display the preprint in perpetuity. It is made available under aCC-BY-NC-ND 4.0 International license.

\section{$1 \quad$ Figure 4.}

N

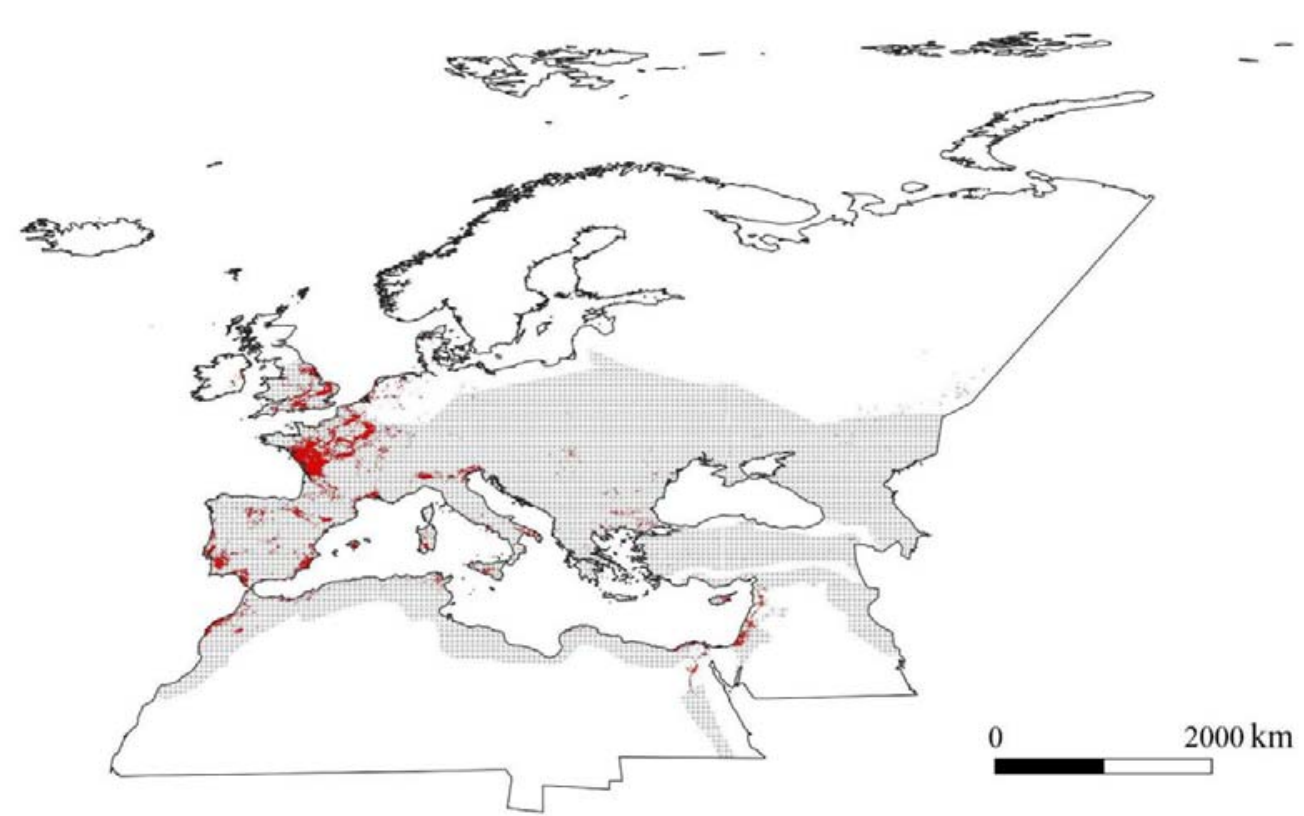

2

3 
1 Figure 1 Occurrence and pseudo-absence points used to model breeding habitat suitability

2 for the Eurasian stone-curlew. Target-group pseudo-absences are observations of other bird

3 species recorded by the same observers of the presence data in the Global Biodiversity

4 Information Facility (GBIF). Kernel density pseudo-absences are points with a spatial density

5 weighted according to a fixed kernel density estimated from the presence points. For target-

6 group and kernel density pseudo-absences, 500 randomly sampled points from the datasets

7 are shown to improve image clarity. The grey area represents the species' range in the

8 Western Palearctic, with the exclusion of the Macaronesian archipelago. Photo by Saverio

9 Gatto.

11 Figure 2 (a) Current breeding habitat suitability map according to the dynamic Maxent 12 model selected to project breeding habitat suitability for the Eurasian stone-curlew under 13 global change scenarios, and (b) response curves for the four environmental variables with 14 the highest percentage contribution in the same model.

16 Figure 3 Cell-wise change of breeding habitat suitability for the Eurasian stone-curlew under 17 four time intervals (2016-2030, 2030-2050, 2050-2070, 2070-2090) and two Representative 18 Concentration Pathways (RCP 4.5, RCP 8.5). S-LULC = Static Land-Use/Land-Cover; D19 LULC = Dynamic Land-Use/Land-Cover.

21 Figure 4 Critical areas for the conservation of the Eurasian stone-curlew. Currently suitable 22 areas predicted to remain suitable under all scenarios of breeding habitat suitability for the 23 species are highlighted in red. Shaded areas represent the species' range in the Western 24 Palearctic, with the exclusion of the Macaronesian archipelago. 
bioRxiv preprint doi: https://doi.org/10.1101/2021.10.04.462847; this version posted October 5, 2021. The copyright holder for this preprint

(which was not certified by peer review) is the author/funder, who has granted bioRxiv a license to display the preprint in perpetuity. It is made available under aCC-BY-NC-ND 4.0 International license.

\section{List of Appendices:}

2

3 Appendix S1. Overview, Data, Model, Assessment and Prediction (ODMAP) protocol

4 (Zurell et al. 2020).

5 